\title{
Circuity in urban transit networks
}

\author{
Jie Huang ${ }^{\mathrm{a}, *, 1}$, David M. Levinson ${ }^{\mathrm{b}}$ \\ a Institute for Transport Studies (ITS), University of Leeds, Leeds LS2 9JT, United Kingdom \\ b Economics, and Urban Systems Research Group, Department of Civil, Environmental, and Geo-Engineering, University of Minnesota, 500 Pillsbury Drive SE, Minneapolis, MN 55455, USA
}

\section{A R T I C L E I N F O}

\section{Article history:}

Received 14 February 2015

Received in revised form 28 August 2015

Accepted 7 September 2015

Available online $\mathrm{xxxx}$

\section{Keywords:}

Circuity

Accessibility

Transit networks

Network efficiency

Mode share

Public transportation

\begin{abstract}
A B S T R A C T
This paper investigates the circuity of transit networks and examines auto mode share as a function of circuity and accessibility to better understand the performance of urban transit systems. We first survey transit circuity in the Minneapolis-St. Paul, Minnesota, region in detail, comparing auto and transit trips. This paper finds that circuity can help to explain mode choices of commuters. We then investigate thirty-five additional metropolitan areas in the United States. The results from these areas show that transit circuity exponentially declines as travel time increases. Moreover, we find that the circuity of transit networks is higher than that of road networks, illustrating how transit systems choose to expand their spatial coverage at the expense of directness and efficiency in public transportation networks. This paper performs a regression analysis that suggests the circuity of transportation networks can estimate transit accessibility, which helps to explain mode share.
\end{abstract}

(c) 2015 Elsevier B.V. All rights reserved.

\section{Introduction}

The design of public transportation networks is not independent of their use. For example, how long a journey by transit takes (compared to alternatives) and how easily destinations are accessed by each mode explains much of the share of public transit use (Owen and Levinson, 2015). Based on studies of self-selection in residential relocation, the preference for transit mode is an important factor (Krizek, 2003; Mokhtarian and Cao, 2008; Cao et al., 2009). People who prefer commuting by transit may choose residences where they can easily access transit stations that are served by routes connecting directly with desired destinations. Following the discussion in these studies, this paper hypothesizes that people who commute by transit select residential locations with less circuitous transit routes than those who do not. This paper compares the circuity of transit and auto home-to-work trips. Investigating this hypothesis can help us understand the selfselection in mode choice by commuters and the need of travelers for direct routes. Hence, the paper first posits the hypothesis (H1) that the transit network circuity of actual transit trips is lower than that of travelers who chose to use a car.

Public transportation networks (including bus and rail) have been built, improved, or expanded in many cities to align network investment policies with transit-oriented development to maximize access to transit systems and encourage transit ridership (Cervero, 2004). In transport

\footnotetext{
* Corresponding author.

E-mail address: tsjh@leeds.ac.uk (J. Huang).

1 Visiting Scholar, Department of Civil, Environmental, and Geo-Engineering, University of Minnesota, USA.
}

planning, urban transit networks are often designed to ensure a large spatial coverage for political or policy reasons (Taylor, 1991), resulting in circuitous lines (Black, 1995; Murray et al., 1998). However, the high indirectness of transit lines that trades off coverage for frequency (Walker, 2012) may discourage ridership, because people could commute by other modes to reduce trip circuity (and thus travel time). A question arises: to what extent do travelers accept the circuity of transit trips?

Increasing transit ridership implies reducing automobile mode share, presently the most widely used commuting mode in every US metropolitan area (American Community Survey, 2012). One reason that more people commute by car instead of by transit is that routes on public transportation networks are more circuitous. Indeed, road networks are typically denser than transit networks, so road networks almost always provide less circuitous routes. With this topological difference in mind, the paper proposes a second hypothesis (H2): that circuity on transit networks is higher than that on road networks for the same trips (Table 7).

Moreover, the correlations between automobile mode share and accessibility in road and transit networks have been previously tested with a local example (Owen and Levinson, 2015) and in multiple metropolitan areas (Levinson, 2012). It has been reported that an increase in transit accessibility may reduce commute time by transit (because jobs are closer to workers and because transit service is thicker), which should reduce automobile mode share. Correlations of circuity, accessibility, and automobile mode share are valuable to investigate. Closing the circle, we propose a third hypothesis (H3): that automobile mode share depends significantly on network circuity and accessibility in road and transit networks. 
In brief, $\mathrm{H} 1$ is investigated in a single area. The study of a local example is more tractable, and allows us to scrutinize different types of trips, helping us begin to understand the structure of transit circuity. Then, the paper addresses $\mathrm{H} 2$ in multiple metropolitan areas in order to discover the range of acceptable transit circuity. Meanwhile, the study of $\mathrm{H} 2$ prepares us to investigate correlations among circuity, accessibility, and automobile mode share (H3) at the level of multiple metropolitan areas.

The paper is organized as follows: Section 2 reviews the relevant literature. Section 3 defines the measures adopted. Data sources are introduced in Section 4, and research methods and sampling strategies are described in Section 5. Results from $\mathrm{H} 1$ from a local example are shown in Section 6, while section 7 displays results from $\mathrm{H} 2$ in multiple metropolitan areas. Section 8 tests $\mathrm{H} 3$ with a regression analysis. Conclusions from this paper are presented in Section 9.

\section{Literature review}

\subsection{Circuity}

Circuity is defined as the ratio of the shortest network distance over Euclidean distance between one origin-destination pair (Levinson and El-Geneidy, 2009; Barthélemy, 2011). For a trip between origin $i$ and destination $j$, circuity is calculated as follows:

$C_{i j}=\frac{D_{i j}^{n}}{D_{i j}^{e}}$,

where $C_{i j}$ is the circuity of a trip with origin $i$ and destination $j$ (i.e. an OD pair), $D_{i j}^{e}$ denotes the Euclidean distance and $D_{i j}^{n}$ denotes the shortest network distance between origin $i$ and destination $j$. Hence, the theoretical minimal value of circuity is 1 when the shortest network distance equals the Euclidean distance. The average circuity of all trips can be used to assess the global performance of network (Vragović et al., 2005). The lower the value of circuity, the more efficient is the network. In road networks, the average circuity was estimated around 1.2 (Newell, 1980). For transit-station catchments, the average circuity was found to be between 1.21 and 1.23 (O'Sullivan and Morrall, 1996). The average circuity may be used in estimating the travel distance (Ballou et al., 2002), as it represents the efficiency of road networks.

More recently, Levinson and El-Geneidy (2009) investigated the circuity in road networks of home-to-work trips in twenty metropolitan areas, and the average circuity was lower for real trips than similar random trips. With a dataset of randomly generated trips for networks from 1990, 2000, and 2010, Giacomin and Levinson (2015) found the circuity of networks generally has increased over time; namely, road networks have become less efficient in fifty metropolitan areas. But Barrington-Leigh and Millard-Ball (2015) argue that networks recently have stopped becoming less efficient, as more well-connected new suburban networks are now being built. The circuity of random OD pairs has been found to be higher than that of real trips (Levinson and ElGeneidy, 2009). In other words, real travelers select OD pairs that are less circuitous than random OD pairs, perhaps because such trips are more efficient or appear more efficient. Real trips are posited to select for lower cognitive burden; that is, they require fewer turns (or thoughts about navigation) on the part of travelers. They also showed the value of investigating the circuity by random trips since, in some areas (or historically), we may lack real trip records by modes. Though many studies have studied the average circuity of trips on road networks, the average circuity in transit networks has not been surveyed well. A study by Lee $(1998,2008)$ explained how circuity could examine the topology of transit networks in a synthetic network, and developed a series of measures. Lee et al. (2015) adopted those measures in the investigation of the relationship of circuity (directness) on mode shares for transit systems in five cities in Korea, at the transportation analysis zone (TAZ) level. Our paper investigates the average circuity of real and random trips (selected at the census block level) in the transit networks of 36 metropolitan areas.

A transportation network (transit or road network) includes two elements: a set of nodes and a set of links connecting these nodes. Following the definition of circuity for a trip (Eq. (1)), Barthélemy (2011) defines the average circuity for a single node:

$C_{i}=\frac{1}{N-1} \sum_{j} C_{i j}$

where $N$ denotes the total number of nodes in the network and $j$ represents the total number of nodes connecting node $i$. Circuity of a node measures how accessible the node is in the network. The smaller $C_{i}$ is, the easier it is to reach the node $i$. Measuring the circuity of a node has been used to find the most accessible node in a transportation network (Crucitti et al., 2006; Porta et al., 2009).

\subsection{Transit network performance}

In assessing the performance of transit network structures, following the study of Lam and Schuler (1982), researchers have explored the complexity and robustness from the topology aspect, and found network centrality to be an emergent property (Derrible, 2012; Derrible and Kennedy, 2009, 2010). Furthermore, Mishra et al. (2012) measured the connectivity of transit networks in multiple levels, investigating nodes, lines, transfer centers, and regions. Roth et al. (2012) studied the topological evolution of transit networks. Studies on topological characteristics can help us understand the performance of transit systems (Black, 2003); however, these studies do not consider traveler behavior or response to topological changes.

Based on the empirical literature from mode choice models, walking and waiting times were weighted as two to five times more onerous than in-vehicle transit travel time (Pratt et al., 1981). Transfers not only extend the travel time but also were estimated to impose penalties that were equivalent to 5-to-15 min of invehicle time. One possible reason for time penalties considered by commuters is that transfers increase the cognitive burden of travelers. In other words, indirectness caused by transfers reduces transit ridership more than a simple consideration of travel time would suggest. Considering the various components of transit trips, we seek the shortest travel time route on transit networks, including invehicle travel, time to access/egress, and transfer time. However, in our analysis, the shortest route is measured with the unweighted travel time.

When the comparison of the circuity between real transit and auto trips may help to explain individual mode choices as the hypothesis proposed, one further question is whether automobile and transit circuity could explain aggregate mode share. Levinson (2012) reported that an increase in accessibility reduced the commute time, and that made the automobile mode share decrease. Owen and Levinson (2015) showed that accessibility explained mode share at the census tract level. As both circuity and accessibility have influence on mode share, is there some correlation between these two measures? Based on the discussion after Eq. (2), correlations between circuity and accessibility likely exist. This paper investigates the correlations of circuity, accessibility, and auto mode share in multiple metropolitan areas.

\section{Definitions}

\subsection{Average circuity of trips}

In this paper, we measure the average circuity of trips by a particular mode to investigate the performance of transportation networks. 
Following Eq. (1), the average circuity of trips by mode $m$ (i.e. $C_{m}$ ) is given by

$C_{m}=\frac{\sum C_{m, i j}}{Q}$

where $Q$ denotes the total number of trips in the area studied. To investigate the mode choice of commuters, the average transit circuity of trips $\left(C_{\text {Transit }}\right)$ and the average auto circuity of trips $\left(C_{\text {Auto }}\right)$ will be estimated respectively for each area.

\subsection{Weighted accessibility}

For the analysis of correlations between circuity and accessibility, this section gives the definition of accessibility that will be used. Here, accessibility has been defined as the number of job locations that can be reached within a time threshold, since reports (Levinson, 2013; Owen and Levinson, 2014) provided the number of job locations in a certain time threshold by driving and transit respectively. As the number of reachable job locations rises with travel time thresholds, the closer job locations are more attractive and weighted higher by commuters in the application of travel choice. So jobs reachable within the shortest time threshold should be weighted most heavily, and jobs are given decreasing weights as travel time increases. Then this paper considers the weighted accessibility that can be defined as follow

$a_{w}=\sum_{t}\left(a_{t}-a_{t-10}\right) \times e^{\theta t}, \quad t=10,20,30, \ldots, 60 \mathrm{~min}$,

where $a_{w}$ denotes weighted accessibility for the whole area and $a_{t}$ and $a_{t}-10$ represent the accessibility value within each time threshold, which, for this paper, are based on previously calculated and published numbers. Based on Levinson and Kumar (1994), the decay coefficient used is $\theta=-0.08$. With Eq. (4), the sum of weighted accessibility in all time periods $a_{w}$ can be obtained for each area. Then each area has weighted accessibility by automobile (i.e. $a_{\text {Auto }}$ ) and transit (i.e. $a_{\text {Transit }}$ ).

\section{Data}

In the Minneapolis-St. Paul region, trips are sourced from the 2010 Travel Behavior Inventory (collected between 2010 and 2012) (TBI, 2013) that records where, when, and how commuters travel. Our analysis includes all home-to-work trips (302 transit trips and over 8000 car trips). Note that the definition of a transit trip includes a primary mode (such as bus, light rail, or commuter rail) with walking as a mode of access/egress. We thus exclude automobile-access transit trips (e.g., parkand-ride or kiss-and-ride trips). Automobile trips are defined as trips with the single mode of driving, and exclude carpools and transit access trips. Chained trips are also excluded from the analysis.

The General Transit Feed Specification (GTFS, 2014) provides a common format for public transportation schedules and associates geographic information. For all areas studied, schedules of public transportation systems were sourced from publicly available GTFS data. For example, GTFS data gave the transit schedule in November, 2011, in Minneapolis-St. Paul, Minnesota, to be compatible with the TBI. For other areas, GTFS data from January 2014 were used, consistent with the accessibility data described below.

Meanwhile, data on road networks in the areas studied are provided by Open Street Map (OSM, 2014), a collaborative project to create a free, editable map worldwide. For instance, the OSM road network for Minneapolis-St. Paul includes 154,571 road segments (links). It is worth noting that OSM data are continuously updated, and so represent the state of the network at the time of download (Fall 2014). Since the road network changes slowly, differences between the dates of OSM and GTFS networks will not significantly affect results.

Additionally, for the investigation of circuity, accessibility, and automobile mode share, this paper obtains the accessibility data from
'Access Across America' reports (Levinson, 2013; Owen and Levinson, 2014) and mode share data from the American Community Survey (2012). From these data sources, we analyze transit circuity in the Minneapolis-St. Paul region in Sections 6 and 7. Moreover, we use OSM, GTFS, accessibility, and mode share data of 35 additional regions for the analysis in Sections 7 and 8.

\section{Research methods and sampling}

\subsection{Research methods}

Measuring circuity among trips obtained from empirical data and those randomly generated in transportation networks can help us better investigate network efficiency, because we could present how the network serves demand overall (Giacomin and Levinson, 2015; Levinson and El-Geneidy, 2009). Moreover, the investigation of random trips may be helpful when the data about home-to-work trips are limited in some areas or historically. With the hypotheses proposed, our paper further tests implications about travel responses to network structures in the form of circuity. In order to compare the transit and auto circuity for transit trips, automobile trips, and trips randomly generated, research methods are developed below for the analysis in the Minneapolis-St. Paul region.

Data about transit trips (such as the location of origins and destinations or departure time) are sourced from TBI records so that the spatial coverage of 302 real transit trips can be determined. Within the coverage determined by real transit trips in the Minneapolis-St. Paul region, we randomly selected 300 real automobile trips from the TBI data. For the generation of random trips, we randomly generated coordinates of 300 origins and 300 destinations across the spatial footprint of real transit trips in the Minneapolis-St. Paul region. Each origin was randomly matched to one destination giving one OD pair, constrained so that each destination was selected once. Moreover, the trip length of random trips on road networks was constrained to have the same distribution as real transit trips. Because the majority of transit trips in the Minneapolis-St. Paul region are within 10-70 min of travel time and the Euclidean distance between origin and destination is within $21 \mathrm{~km}$, automobile trips and those randomly generated keep these ranges consistent. In addition, since public transportation is a scheduled service, the shortest travel-time transit path, and thus transit circuity, vary by time of day. To control for this, the period of departure time for random trips is the same as for real transit trips.

This paper finds the shortest travel time route by transit for three types of trips (real transit users, real automobile users, and random OD pairs) in OpenTripPlanner (OTP, 2014) software with GTFS and OSM data. In this step, we set the allowed waiting time at origin as zero in the OTP as, in such cases, the trip travel time is estimated from departure time in the TBI data or from the predetermined time for random trips. As the shortest travel time route by transit includes the walking time to access/egress and travel time along transit lines, the network distance in the estimation of circuity consists of the walking routes on road networks and the routes on transit networks.

Importing the origins and destinations of all trips using Geographic Information System (GIS) software (ArcGIS 10.2), we calculated the shortest road network distance of trips with the Network Analyst tool. In such cases, points join the road network via the most adjacent link. With the impedance of trip length, one-way restrictions, and allowed U-turns at junctions, Dijkstra's (1959) algorithm was used to find the shortest paths. The connectivity policy was set as Any Vertex when we generated the Network Dataset for each metropolitan area.

For the analysis of circuity, accessibility, and mode share in transportation networks, this paper calculates the weighted accessibility and sources the automobile mode share for each metropolitan area, as well as the Minneapolis-St. Paul region. Note that the report by Owen and Levinson (2014) observed transit accessibility in Core Based Statistical Areas (CBSA) in the United States, but the geometries of areas 
Table 1

Comparison of the average distance of shortest travel time routes by transit

$D_{i j}^{\text {Transit }}(\mathrm{km})$, the average distance of shortest routes by auto

$D_{i j}^{\text {Auto }}(\mathrm{km})$, the Euclidean distance $D_{i j}^{e}(\mathrm{~km})$, transit circuity $C_{\text {Transit }}$ and auto circuity $C_{\text {Auto }}$ and their stand deviations $\sigma$ in the Minneapolis-St. Paul region.

\begin{tabular}{|c|c|c|c|c|c|c|c|c|c|c|}
\hline & \multicolumn{2}{|l|}{$D_{i j}^{\text {Transit }}$} & \multicolumn{2}{|l|}{$D_{i j}^{\text {Auto }}$} & \multicolumn{2}{|l|}{$D_{i j}^{e}$} & \multicolumn{2}{|l|}{$C_{\text {Transit }}$} & \multicolumn{2}{|l|}{$C_{\text {Auto }}$} \\
\hline & mean & $\sigma$ & mean & $\sigma$ & mean & $\sigma$ & mean & $\sigma$ & mean & $\sigma$ \\
\hline Real transit trips & 14.72 & 6.90 & 8.79 & 4.74 & 7.7 & 4.31 & 2.19 & 1.02 & 1.15 & 0.09 \\
\hline Real auto trips & 22.69 & 11.36 & 11.36 & 9.53 & 8.12 & 3.91 & 3.28 & 2.14 & 1.18 & 0.09 \\
\hline Random trips & 24.40 & 9.716 & 9.71 & 10.90 & 9.53 & 4.18 & 2.98 & 1.64 & 1.16 & 0.07 \\
\hline
\end{tabular}

studied in this paper are based on the rectangle map generated by the OSM. Maps from the OSM mainly record areas with high accessibility; other areas with low accessibility and the fringes or edges of metropolitan areas have been excluded. Since this paper used the sum of personweighted accessibility and relatively sparse OD pairs (compared to Owen and Levinson, 2014), the relatively few trips in the fringes or areas with low accessibility are ignored. This does not affect meaningfully the analysis in Section 8.

\subsection{Sampling}

First, the outcome from the OTP suggests that some potential transit trips have large circuity values, but transit users seldom chose a very circuitous route (i.e., routes with high circuity) as they have included the preference of mode choices in residential locations (Mokhtarian and Cao, 2008; Cao et al., 2009). These results may be caused by errors in the official GTFS schedules. The proportion of trips with large transit circuity (over 8 ) is around three percent. The low rate also implies that those trips are affected by bugs in schedules, so they are excluded in the sample. Second, some trips cannot be estimated or have high auto circuity due to the accuracy of the OSM and TBI data, and these trips are also excluded from the sample. Third, if the value of circuity (by automobile or transit) is lower than 1 , the corresponding trips are excluded.

\section{Results H1: real transit, real auto, and random trips}

With the research methods proposed, actual transit trips and automobile trips, and those randomly generated, can be analyzed in the Minneapolis-St. Paul region. For a trip between origin $i$ and destination $j$, the distance of the shortest travel time route by transit $\left(D_{i j}^{\text {Transit }}\right)$, the distance of the shortest distance route on road networks $\left(D_{i j}^{\text {Auto }}\right)$, and the Euclidean distance $\left(D_{i j}^{e}\right)$ between the origin and destination can be calculated. The average distances for three trip types are shown in Table 1. The average distance of transit routes for actual transit trips is much shorter than for automobile trips and random OD pairs. Compared to this large difference, the average distances of routes by automobile are close, so are Euclidean distances. The average circuity of transit, automobiles, and random trips in the Minneapolis-St. Paul region is shown in Table 1. For each trip type, the average transit circuity $C_{\text {Transit }}$ and the average auto circuity $C_{\text {Auto }}$ can be estimated. Since the average distances of routes by automobile are similar, average car circuities in Table 1 only have minor differences, with small standard

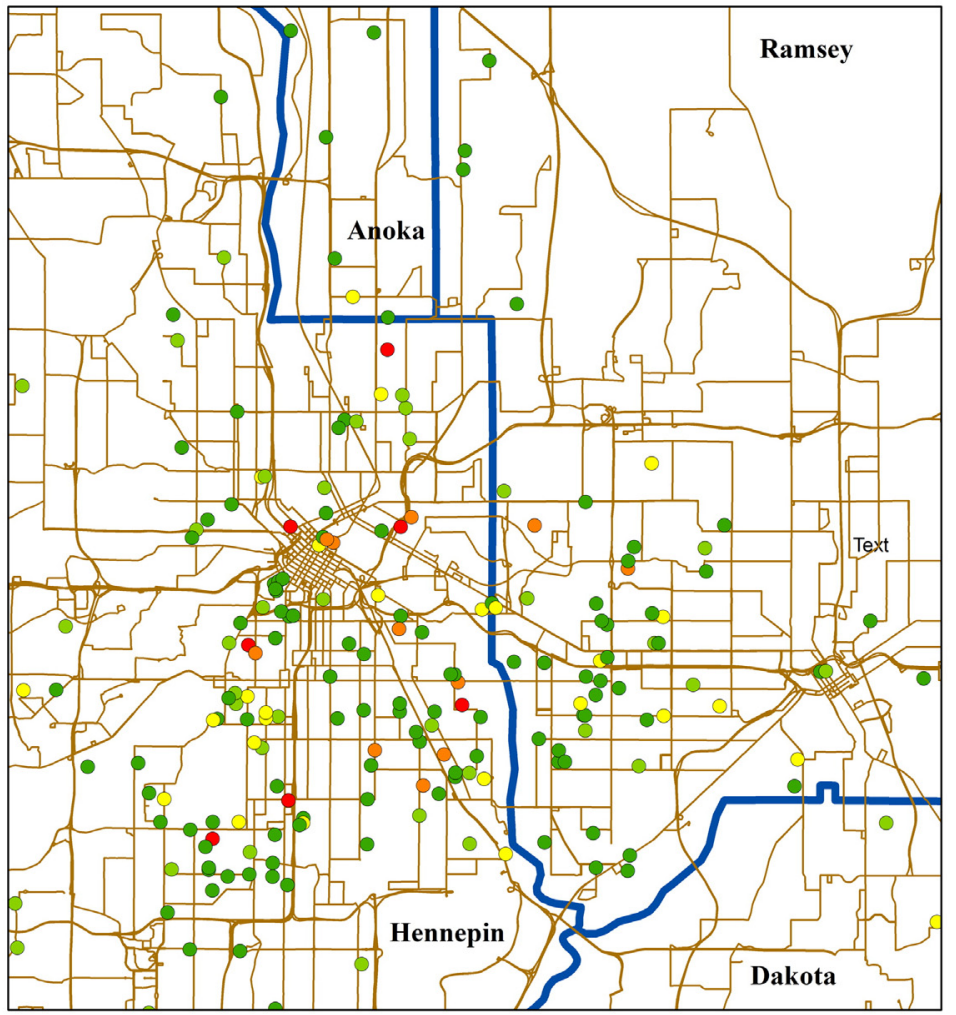

Data Source: Metropolitan Council and the Lawrence Group (2015); 2010 Travel Behavior Inventory (2013), Metropolitan Council.

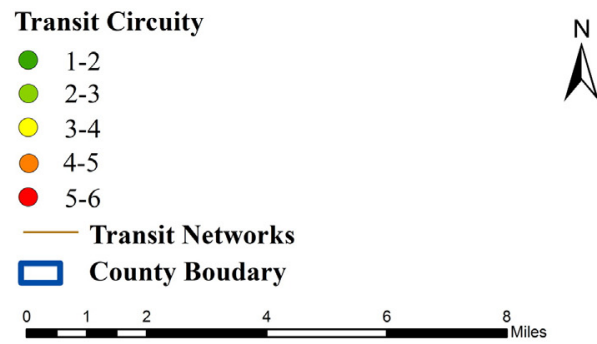

Projection: NAD 1983 UTM zone 15N

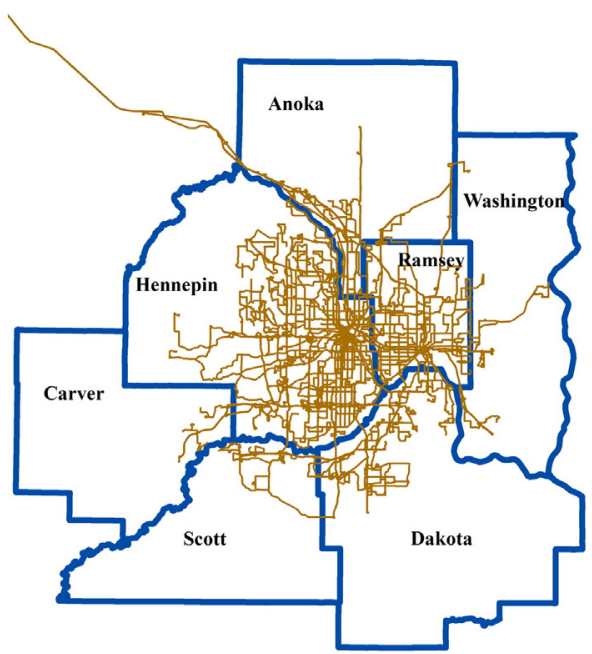

Fig. 1. Transit circuity of each real transit trip in the Minneapolis-St. Paul region in the Travel Behavior Inventory, by origin. 
Table 2

Auto mode share and average circuity $C_{\text {Transit }}, C_{\text {Auto }}$ of trips in seven counties, the Minneapolis-St. Paul Region. (- indicates that there are no real transit trips.).

\begin{tabular}{lllllll}
\hline \multirow{2}{*}{$\begin{array}{l}\text { County } \\
\text { name }\end{array}$} & \multirow{2}{*}{$\begin{array}{l}\text { Auto mode } \\
\text { share }\end{array}$} & & \multicolumn{2}{c}{ Real transit trip } & & \multicolumn{2}{l}{ Random trips } \\
& & $C_{\text {Transit }}$ & $C_{\text {Auto }}$ & & $C_{\text {Transit }}$ & $C_{\text {Auto }}$ \\
\hline Hennepin & 0.8255 & 2.2885 & 1.1550 & & 2.2838 & 1.1569 \\
Ramsey & 0.8455 & 2.0174 & 1.1627 & & 2.9642 & 1.1457 \\
Anoka & 0.8600 & 1.8697 & 1.1009 & & 2.7550 & 1.1527 \\
Carver & 0.8895 & - & - & & 2.9085 & 1.2457 \\
Scott & 0.8929 & - & - & & 3.1570 & 1.1220 \\
Dakota & 0.8983 & 2.2020 & 1.1296 & & 2.9450 & 1.1503 \\
Washington & 0.9163 & 1.4364 & 1.0938 & & 3.3032 & 1.1281 \\
\hline
\end{tabular}

deviations. This provides a fair comparison basis for transit circuity. However, the transit circuity of trips has a larger spread and the coefficients of variation are $50.59 \%, 65.23 \%$, and $55.06 \%$ for transit trips, automobile trips, and random OD pairs respectively. Since transit stops are dense in some parts of the region (e.g., the city center and transit hubs), transit circuity in such regions should be close to the automobile circuity. But, for parts of the region with few transit stops, transit circuity typically should be very high.

In Fig. 1, a map of the transit network in the Minneapolis-St. Paul region is shown (Metropolitan Council and the Lawrence Group, 2015). Meanwhile, origins of real transit trips from the Travel Behavior Inventory are shown with the values of transit circuity. As the transit network mainly covers the region of Hennepin, Ramsey, and Anoka counties, most transit trips occur in those counties. Though there are no records of real transit trips originating in Carver and Scott counties in the Travel Behavior Inventory, the coverage of random trips covers seven counties so that we can compute the average transit circuity of random trips in every county. In Table 2, we observe that automobile mode share should be positively correlated with the transit circuity of random trips.

Fig. 2 displays the decay of transit circuity over the distance interval, which is consistent with the conclusion that the automobile circuity declines with an increase in trip length (Giacomin and Levinson, 2015; Levinson and El-Geneidy, 2009). Fig. 2 corroborates that the transit circuity of real automobile trips is higher than the transit circuity of real transit trips (H1). The significant difference of transit circuity between transit and automobile trips explains, in large part, the choice of modes. People served by very circuitous transit routes are much less likely to use transit than people served by relatively more direct transit routes

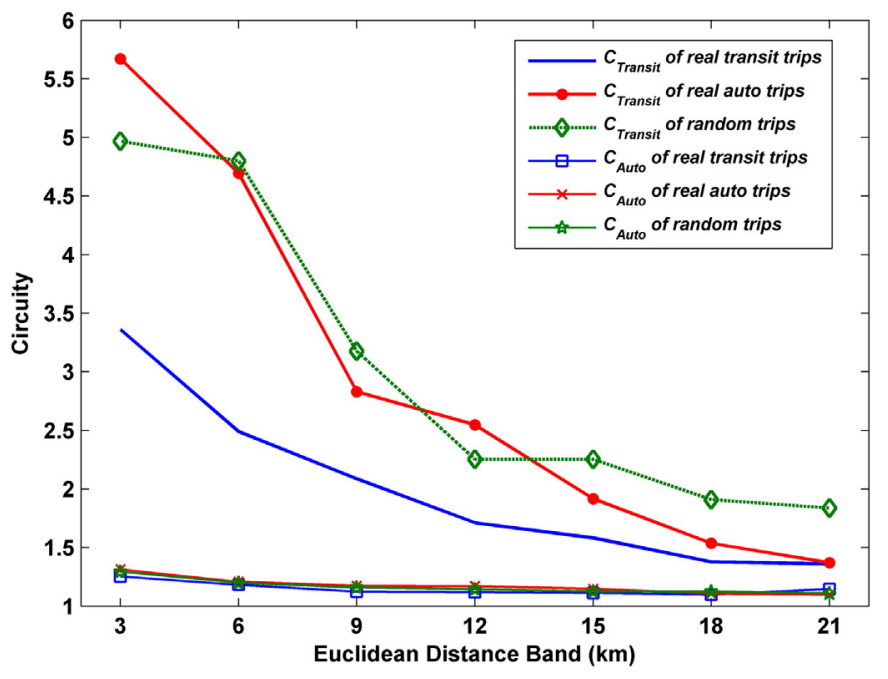

Fig. 2. Circuity in each Euclidean distance interval in the Minneapolis-St. Paul region.
It is observed that trips of short distances have much higher transit circuity. We suspect commuters, in practice, take some off-road routes to get on/off transit systems, which are not reflected in the network (so the transit circuity may be somewhat overstated). Within a transit trip, a large element of circuity relates to the fact that the "first mile" of access or/and the "last mile" of egress may be orthogonal to the scheduled transit service. These elements arise in every transit trip. Similarly, feeder services may be orthogonal to trunk services. But, for long transit trips, the proportion of the orthogonal section of the route decreases with overall trip length. Moreover, we observe that auto circuity serves as the lower limit of transit circuity for all on-road or roadadjacent transit facilities.

Overall, average transit circuity of trips is significantly higher than automobile circuity, since the transit network is designed to provide a large area of coverage so that commuters have a shorter time to access the network. The trade-off with greater spatial coverage is longer invehicle travel times and lower frequencies, so transit trips generally have higher travel times than trips on the road network. The exception is when transit networks are grade-separated and running on more direct off-road facilities. This observation about circuity explains why the transit network has lower overall accessibility, corroborating Levinson (1998).

\section{Results H2: travel time and transit circuity}

Travel time is the most important factor affecting travel behavior. Hence, this paper focuses on the correlation between transit circuity and travel time. As shown in Fig. 3, transit circuity declines as travel time increases. Similar to Giacomin and Levinson (2015), a regression analysis is performed using Eq. (5)

$C_{t}=\beta_{1} t^{\beta_{2}}$

where $t$ represents each travel time interval, $C_{t}$ represents the transit circuity at that interval, $\beta_{1}$ and $\beta_{2}$ are parameters to be estimated.

Table 3 shows the regression results from the Matlab nonlinear regression tool. As shown in Fig. 3, the transit circuity of real transit trips may decay from 3.5. The combination of $\beta_{1}$ and $\beta_{2}$ controls from where and how fast transit circuity declines as travel time increases. The situation where $\beta_{1}>0$ and $\beta_{2}>0$ indicates that the transit circuity exponentially decays as travel time increases. The exponential decay between transit circuity and travel can be found in the cases for real transit trips and randomly generated trips. The goodness of fit $\left(R^{2}\right)$ by transit and random trips is close to one. The exponential decay indicates that transit trips within short travel times have high circuity, like trips

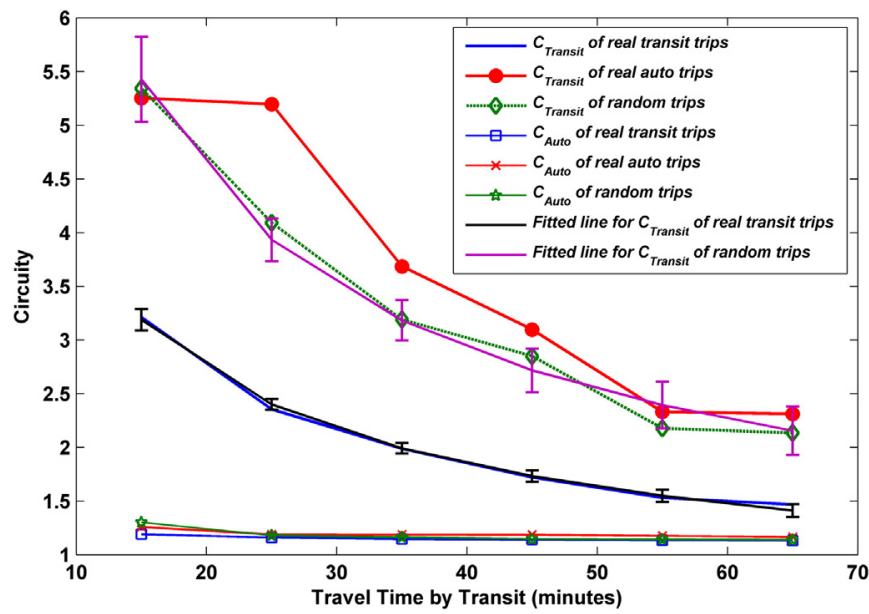

Fig. 3. circuity in each travel time interval in the Minneapolis-St. Paul region. 
Table 3

Regression results of Transit Circuity in the Minneapolis-St. Paul Region.

\begin{tabular}{llll}
\hline Trip name & $\beta_{1}$ & $\beta_{2}$ & $R^{2}$ \\
\hline Real transit trips & 14.3593 & -0.5557 & 0.9971 \\
Random trips & 29.8804 & -0.6300 & 0.9874 \\
\hline
\end{tabular}

with short distances. For a transit trip with a 30-minute travel time, invehicle travel time may be $20 \mathrm{~min}$; but $10 \mathrm{~min}$ is used to access/egress along the circuitous route. Recalling the discussion of "first mile" and "last mile", we may find the low explanatory power of circuity at the short travel time or distance.

Table 3 and the regression in Fig. 3 show that the correlation between transit circuity and travel time by random trips is similar to real transit trips. Hence, the generation of random OD pairs can provide information when we only have limited data about the spatial location of actual trips in multiple areas. Moreover, more evidence from more areas could help us better collaborate findings in the Minneapolis-St. Paul region. To that end, the paper replicates the investigation of transit circuity by random OD pairs for another 35 metropolitan areas in the United States.

In order to generate OD pairs with a proper spatial coverage as home-to-work trips, we first generated 300 destinations and 300 origins within the city center. The coordinate of city center points for each metropolitan area is obtained from the Date and Time (2014) online database. With this nominal city center data, the region of a city center is defined as a circle with a 5-km radius around its center point. Another 300 destinations and 300 origins were randomly generated across the whole OSM rectangular region for that metropolitan area. Each origin is randomly matched to one destination, giving 600 trips for each area. Consequently, an origin and destination pair may represent trips with both ends in the city center, neither end in the city center, or one end in the center and one not. In these 35 areas studied, trips up to 90 min of travel duration are included in the analysis, and the travel time distribution is kept constant across the areas studied. The time distribution is similar to that in the Minneapolis-St. Paul region, where the number of trips in the time interval firstly increases and then decays as travel time increases. In such cases, the number of trips has a peak between 40 and $60 \mathrm{~min}$ in these additional areas. Note that the range of travel time by random trips in the Minneapolis-St. Paul region is extended to fall within 90 min in this section.

To test whether 600 trips are sufficient to ascertain circuity, a more detailed analysis is conducted for the Chicago region. Fig. 4 shows that the transit circuity slightly varies in a small range from 600 up to 2000

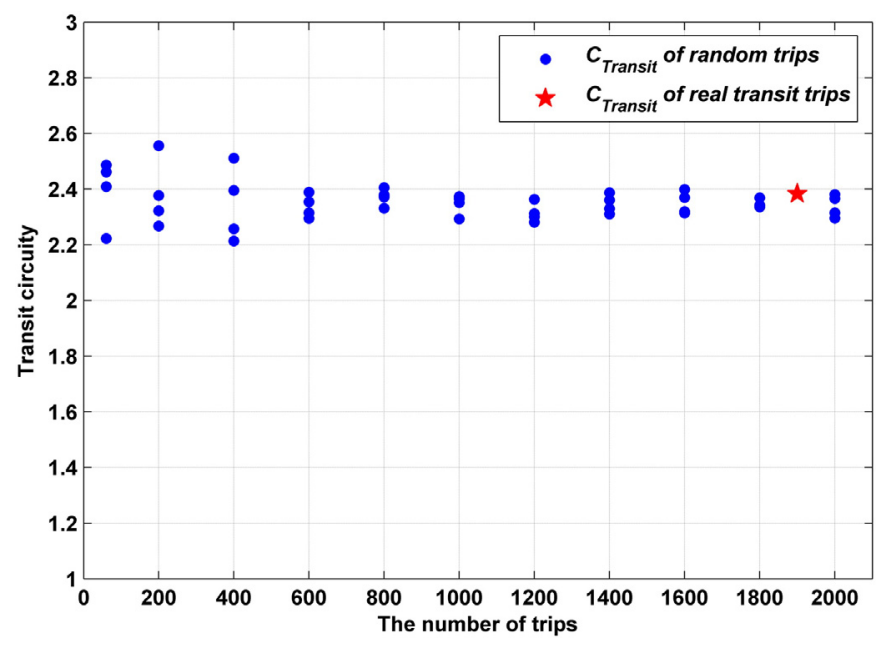

Fig. 4. Sensitivity analysis of trip number and transit circuity in Chicago. random trips. The average circuity of real transit trips from the 2007 household survey in Chicago (MTSA, 2007) is 2.3842 and that of random trips is 2.3275 . We have performed a two-tailed T-test with the significance level of 0.05 to examine if the average values of circuity have differences for two samples. The $t$-value $|t|>1.960$, which indicates the variations of average circuity in two samples, is small. It shows that the number of random trips is sufficiently large to generate reliable conclusions. This paper surveys the average transit circuity of random trips due to the limited data from household surveys.

Results are shown in Figs. 5 and 6. In Fig. 5, the decay between transit circuity and travel time can be observed in five metro areas. Similar to the analysis shown in Table 3, we then used the same regression method as Eq. (5) and the result of the regression is shown in Appendix 1. The exponential decay $\left(\beta_{1}>0\right.$ and $\left.\beta_{2}<0\right)$ has been observed across metropolitan areas with high goodness of fit. The auto circuity $C_{\text {Auto }}$ is in the expected range, which supports the use of the random trip generation method. In Fig. 6, the automobile mode share of these areas is ranked and the average transit circuity of random trips and the ratio of $C_{\text {Auto }}$ to $C_{\text {Transit }}$ are listed. The average transit circuity is higher than automobile circuity for the same sample of random trips (i.e., $C_{\text {Auto }} / C_{\text {Transit }}<1$ ) and the transit circuity is variable compared to automobile circuity (see the standard deviation in Appendix 1). One conjecture from Fig. 6 is that the ratio of $C_{\text {Auto }}$ to $C_{\text {Transit }}$ may increase as automobile mode share decreases. This should be caused by two variations: (i) the average automobile circuity increases and/or (ii) the average transit circuity decreases as automobile mode share decreases (non-automobile mode share increases). However, the correlation between automobile mode share and circuity is not obvious and it needs more discussion, as shown in Section 8.

\section{Results H3: circuity, accessibility, and mode share}

\subsection{Correlation of circuity, accessibility, and mode share}

The variation between transit and automobile circuity may explain mode share in metropolitan areas. Because either transit or road networks become efficient with lower circuity; they may attract more commuters. Meanwhile, transit mode share increases with efficient accessibility of transit or road networks (Levinson, 2012). Considering these possible relationships, we examine both circuity and accessibility on both transit and road networks in order to better explain mode share.

For the analysis of automobile mode share $M_{\text {Auto }}$, we have four prospective explanatory variables, automobile circuity $C_{\text {Auto }}$, accessibility $a_{\text {Auto }}$, transit circuity $C_{\text {Transit, }}$ and transit accessibility $a_{\text {Transit }}$. In order to investigate correlations among these explanatory variables, this paper first looks at their correlation matrix. In the metropolitan areas studied, automobile mode share ranges from 56.55 to $92.65 \%$. As shown in

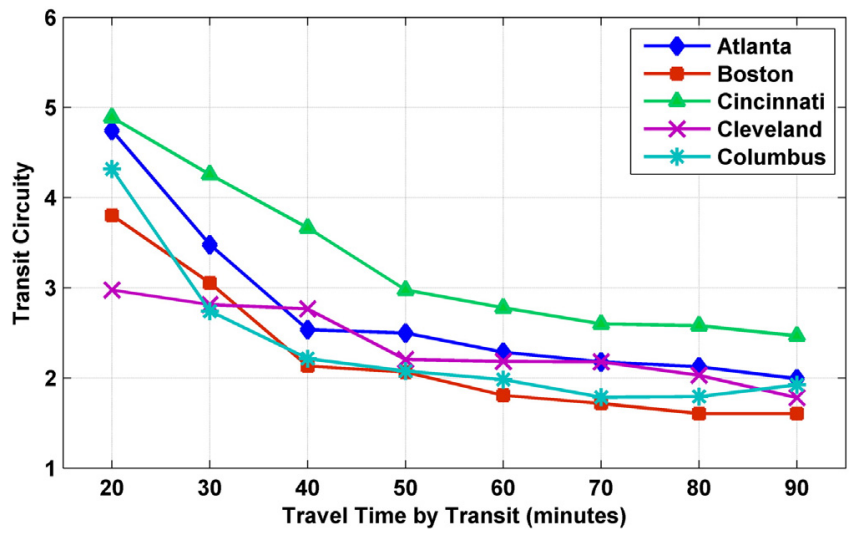

Fig. 5. Decay of Transit Circuity in metropolitan areas. 


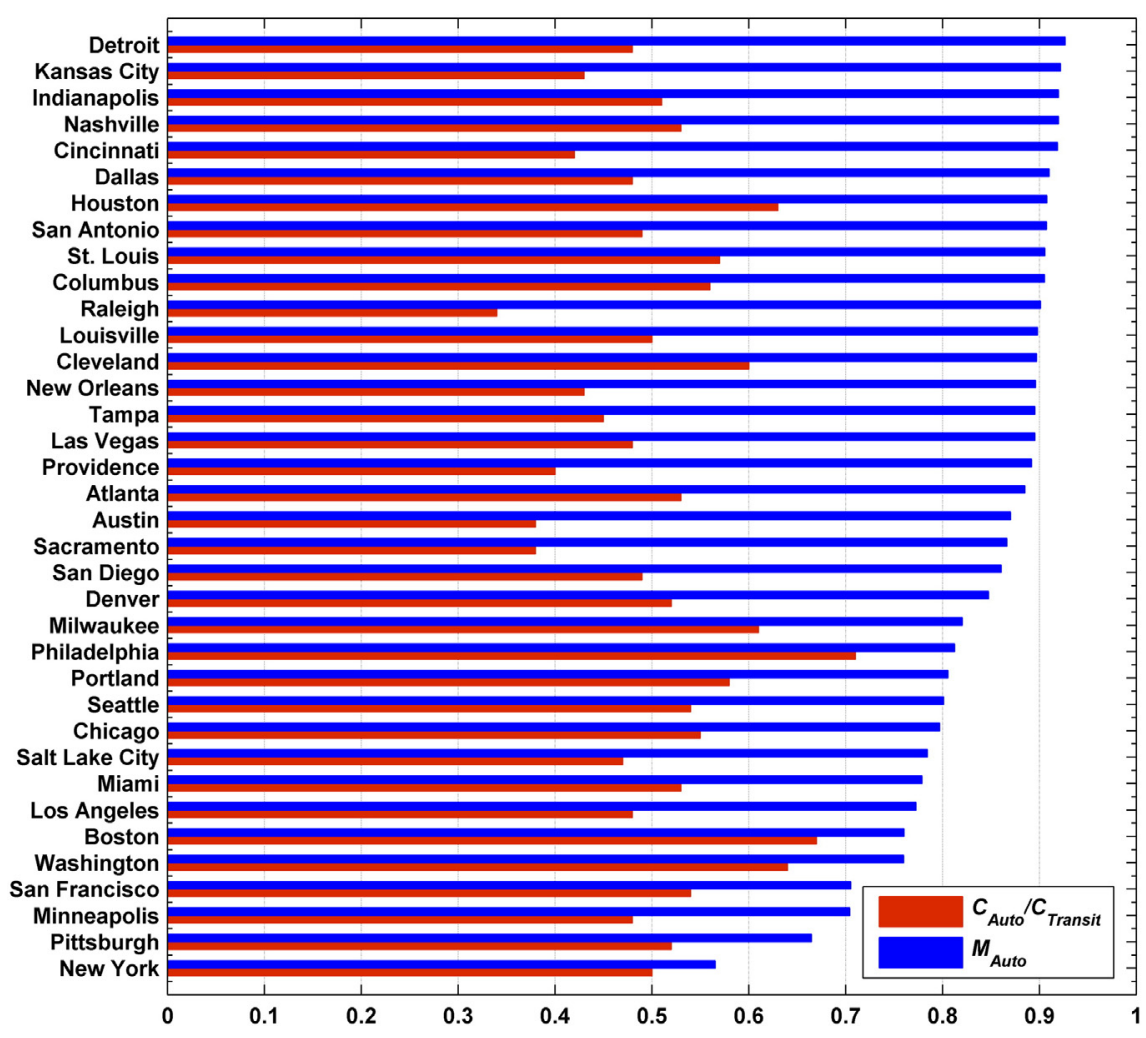

Fig. 6. Transit and auto circuity (i.e. $C_{\text {Transit }}$ and $C_{\text {Auto }}$ ) and auto mode share (i.e. $M_{\text {Auto }}$ ) in 36 metropolitan areas.

Table 4, automobile circuity is negatively correlated with automobile mode share; because high circuity on road networks could reduce the network efficiency and, thus, automobile mode share decreases. Transit accessibility is also negatively correlated with automobile mode share, since the high accessibility of transit networks can attract more commuters and, thus, fewer people commute by driving. Perhaps unexpectedly, automobile accessibility is negatively correlated with automobile mode share. This corroborates previous findings by Levinson (2012) and is posited to be due to the high correlation $(0.6645)$ between automobile and transit accessibility. Large cities have both high automobile and transit accessibility, and tend to have relatively low automobile mode shares. Additionally, automobile and transit circuity are significantly correlated as automobile and transit accessibility, which may indicate the possible correlation between the circuity and accessibility.

\subsection{Circuity and accessibility}

Compared to circuity, transit and automobile accessibility are significantly correlated with automobile mode share (see Table 4). A question remained, however: how does circuity of transportation networks influence automobile mode share? Based on the discussion below, Eq. (2), and the statements of correlation matrix, there may be some correlation

Table 4

Correlation Matrix of Circuity, Accessibility and Mode Share $M_{\text {Auto }}$ in 36 metropolitan areas.

\begin{tabular}{lrrrrr}
\hline & $M_{\text {Auto }}$ & \multicolumn{1}{c}{$C_{\text {Auto }}$} & $A_{\text {Auto }}$ & $C_{\text {Transit }}$ & $a_{\text {Transit }}$ \\
\hline$M_{\text {Auto }}$ & 1 & & & & \\
$C_{\text {Auto }}$ & -0.2243 & 1 & & & \\
$a_{\text {Auto }}$ & -0.5865 & -0.1007 & 1 & & \\
$C_{\text {Transit }}$ & 0.1761 & 0.5378 & -0.2896 & 1 & \\
$a_{\text {Transit }}$ & -0.7460 & 0.3768 & 0.6645 & -0.0698 & 1 \\
\hline
\end{tabular}

between circuity and accessibility in transportation networks. We use the following model:

$a_{\text {Transit }}=\tau_{1} C_{\text {Auto }}+\tau_{2} C_{\text {Transit }}+\tau_{3}$,

where $\tau_{1}, \tau_{2}$ and $\tau_{3}$ are the coefficients to be estimated.

Table 5 shows the result of regression analysis between circuity and accessibility. It can be seen that both automobile and transit circuity are statistically significant factors affecting transit accessibility. A one-unit increase of transit circuity decreases metropolitan average transit accessibility (by 5912 weighted jobs), because increases in circuity decrease the efficiency of transit systems for users. Perhaps less obviously, a one-unit increase of automobile circuity increases transit accessibility. When, after controlling for transit circuity, road networks are less efficient, more people may use transit, improving transit service (a positive feedback effect of transit service and use dubbed the "Mohring Effect" (Mohring, 1972; Bar-Yosef et al., 2013) in the field), and thus improving transit accessibility. The accessibility of transit networks can be estimated from the model in Eq. (6) and $\hat{a}_{\text {Transit }}$ denotes the transit accessibility estimated from $C_{\text {Auto }}$ and $C_{\text {Transit }}$. With this model, we conclude that automobile and transit circuity reflect the efficiency of road and transit networks and influence transit accessibility.
Table 5

Results in OLS regression for transit accessibility.

\begin{tabular}{llllc}
\hline$a_{\text {Transit }}$ & Coef. & Std. err & $t$ & $P>|t|$ \\
\hline$C_{\text {Auto }}$ & $62,875.82$ & $19,330.43$ & 3.25 & 0.003 \\
$C_{\text {Transit }}$ & -5912.791 & 2764.528 & -2.14 & 0.040 \\
Constant & $-60,002.24$ & $21,729.12$ & -2.76 & 0.009 \\
& & & Observations & 36 \\
& & & $R^{2}$ & 0.2465 \\
& & & Prob $>F$ & 0.0094
\end{tabular}




\subsection{Regression analysis for mode share}

This section tests how accessibility by automobile and transit affects automobile mode share in a bivariate model. Since we have censored data of mode share, a logit function is given by:

$\operatorname{logit}(p)=\log \left(\frac{M_{\text {Auto }}}{1-M_{\text {Auto }}}\right)$

where $M_{\text {Auto }}$ denotes automobile mode share in a metropolitan area. The estimated transit accessibility ( $\hat{a}_{\text {Transit }}$ ) from the preceding section and automobile accessibility (Levinson, 2013) can be used in the regression for automobile mode share, with the regression model thus:

$\operatorname{logit}(p)=\alpha_{0}+\alpha_{1} \alpha_{\text {Auto }}+\alpha_{2} \hat{a}_{\text {Transit }}$,

where $\alpha_{0}, \alpha_{1}$ and $\alpha_{2}$ are coefficients to be estimated. The regression results are shown in Table 6 . The transit accessibility estimated $\hat{a}_{\text {Transit }}$ from transit and automobile circuity shows statistical significance in the regression model (Eq. (8)). As the coefficients estimated by $\alpha_{\text {Auto }}$ and $\hat{a}_{\text {Transit }}$ are negative, metropolitan areas with higher transit accessibility have lower automobile mode share (higher non-automobile mode share). Hence, a negative correlation exists between $\hat{a}_{\text {Transit }}$ and $M_{\text {Auto }}$, which has been shown in Table 4. Similarly, those areas with higher automobile accessibility also have lower automobile mode share, as car accessibility is correlated with density, crowding, and congestion.

\section{Conclusions}

This paper adopted circuity, the ratio of network to Euclidean distance, to investigate attributes of public transit networks. For the Minneapolis-St. Paul region, transit circuity is compared to that of road networks among real transit trips, real automobile trips and random OD pairs. Transit circuity for transit users is lower than transit circuity for automobile users and for random trips, which helps to explain mode choice. As the comparison of transit circuity between transit and automobile trips show how transit systems serve and explain travel behavior, this analysis may be generalized in other cities to help us measure performance of transit systems.

For thirty-six metropolitan areas in the United States, trips randomly generated with systematic methods were examined. The results showed that average transit circuity is higher than that in road networks. The higher value of transit circuity showed that transit networks have been designed to ensure a large spatial coverage, giving circuitous routes for commuters. In practice, trips on transit networks in the United States are always more circuitous on average than on road networks. Moreover, the exponential decay between transit circuity and travel time shows the possible range of transit circuity in urban transit networks (from 1.5 to 6), which is useful in the design of transit lines. It also shows that increases in travel time could reduce the transit circuity, as the distance of transit routes is a large proportion of total travel distance. This implies that the 'first mile' to access or the 'last mile' to egress are a large element of high transit circuity. This paper has displayed the variation of transit circuity in 36 different metropolitan areas in the U.S., demonstrating the value of measuring circuity in transit networks.

Table 6

Results in OLS regression for auto mode share.

\begin{tabular}{lllll}
\hline $\operatorname{logit}(p)$ & Coef. & Std. err & $t$ & $P>|t|$ \\
\hline$a_{\text {Auto }}$ & $-4.75 \times 10^{-6}$ & $-1.19 \times 10^{-6}$ & -4.00 & 0.000 \\
$\hat{a}_{\text {Transit }}$ & $-4.92 \times 10^{-5}$ & $-2.09 \times 10^{-5}$ & -2.35 & 0.025 \\
$\alpha_{0}$ & 2.6482 & 0.1937 & 13.67 & 0.000 \\
& & Observations & 36 \\
& & & $R^{2}$ & 0.4191 \\
& & & Prob $>F$ & 0.0001 \\
\hline
\end{tabular}

Moreover, this paper showed that circuity helps to explain transit accessibility to jobs and that transit accessibility can help to explain much of the variation in mode share across metropolitan areas. The regression analysis suggests that transit circuity may affect accessibility of transit networks and then commuting mode share. This finding showed empirically the correlation between regional accessibility and circuity.

\section{Acknowledgments}

The authors thank the editor and two anonymous reviewers for their valuable comments which help us improve the manuscript. The authors would like to thank Andrew Owen for guidance in applying OpenTripPlanner. The authors also thank Jessica Schoner, Martin Brosnan and Brendan Murphy for their help during Jie's stay at the University of Minnesota, where this work was conducted.

\section{Appendix 1}

Table 7

Auto circuity and regression results of transit circuity as a function of time for random OD pairs.

\begin{tabular}{|c|c|c|c|c|c|c|c|}
\hline Metropolitan area & $C_{\text {Auto }}$ & $\sigma_{\text {Auto }}$ & $C_{\text {Transit }}$ & $\sigma_{\text {Transit }}$ & $\beta_{1}$ & $\beta_{2}$ & $R^{2}$ \\
\hline Atlanta & 1.24 & 0.18 & 2.33 & 0.96 & 19.36 & -0.53 & 0.96 \\
\hline Austin & 1.27 & 0.27 & 3.34 & 1.48 & 49.86 & -0.66 & 0.96 \\
\hline Boston & 1.24 & 0.22 & 1.86 & 0.60 & 16.79 & -0.55 & 0.97 \\
\hline Chicago & 1.29 & 0.24 & 2.33 & 0.98 & 17.61 & -0.58 & 0.99 \\
\hline Cincinnati & 1.29 & 0.28 & 3.05 & 1.30 & 15.76 & -0.42 & 0.97 \\
\hline Cleveland & 1.28 & 0.44 & 2.14 & 0.93 & 6.45 & -0.27 & 0.88 \\
\hline Columbus & 1.26 & 0.20 & 2.23 & 1.05 & 18.14 & -0.55 & 0.91 \\
\hline Dallas & 1.19 & 0.20 & 2.48 & 1.27 & 38.77 & -0.68 & 0.99 \\
\hline Denver & 1.22 & 0.12 & 2.36 & 1.31 & 27.83 & -0.66 & 0.96 \\
\hline Detroit & 1.23 & 0.21 & 2.54 & 1.33 & 19.14 & -0.56 & 0.98 \\
\hline Houston & 1.20 & 0.16 & 1.91 & 0.50 & 5.06 & -0.24 & 0.96 \\
\hline Indianapolis & 1.19 & 0.17 & 2.31 & 0.96 & 8.94 & -0.34 & 0.93 \\
\hline Kansas City & 1.24 & 0.15 & 2.87 & 1.48 & 17.16 & -0.44 & 0.93 \\
\hline Las Vegas & 1.23 & 0.15 & 2.57 & 1.34 & 32.90 & -0.67 & 0.98 \\
\hline Los Angeles & 1.22 & 0.16 & 2.55 & 1.44 & 26.36 & -0.64 & 1.00 \\
\hline Louisville & 1.33 & 0.31 & 2.65 & 1.00 & 15.31 & -0.45 & 0.94 \\
\hline Miami & 1.25 & 0.16 & 2.35 & 1.17 & 44.20 & -0.72 & 0.95 \\
\hline Milwaukee & 1.17 & 0.12 & 1.92 & 0.51 & 5.87 & -0.29 & 0.96 \\
\hline Minneapolis & 1.23 & 0.03 & 2.55 & 1.09 & 29.88 & -0.63 & 0.99 \\
\hline Nashville & 1.30 & 0.32 & 2.48 & 0.99 & 14.04 & -0.44 & 0.95 \\
\hline New Orleans & 1.44 & 0.44 & 3.32 & 2.00 & 20.02 & -0.46 & 0.97 \\
\hline New York & 1.47 & 0.37 & 2.97 & 1.19 & 12.84 & -0.38 & 0.99 \\
\hline Philadelphia & 1.23 & 0.23 & 1.74 & 0.56 & 15.59 & -0.55 & 0.89 \\
\hline Pittsburgh & 1.30 & 0.15 & 2.47 & 1.25 & 41.94 & -0.68 & 0.90 \\
\hline Portland & 1.24 & 0.16 & 2.16 & 0.86 & 23.18 & -0.59 & 1.00 \\
\hline Providence & 1.43 & 0.30 & 3.56 & 1.40 & 29.74 & -0.55 & 0.97 \\
\hline Raleigh & 1.33 & 0.36 & 3.91 & 1.39 & 21.68 & -0.43 & 0.97 \\
\hline Sacramento & 1.24 & 0.12 & 3.31 & 1.91 & 33.90 & -0.57 & 0.90 \\
\hline Salt Lake City & 1.32 & 0.29 & 2.80 & 1.41 & 15.22 & -0.45 & 0.95 \\
\hline San Antonio & 1.27 & 0.36 & 2.60 & 1.10 & 24.15 & -0.59 & 0.98 \\
\hline San Diego & 1.29 & 0.20 & 2.65 & 1.54 & 34.37 & -0.63 & 0.93 \\
\hline San Francisco & 1.23 & 0.14 & 2.27 & 0.99 & 21.30 & -0.59 & 0.94 \\
\hline Seattle & 1.29 & 0.29 & 2.38 & 1.07 & 12.63 & -0.44 & 0.86 \\
\hline St. Louis & 1.29 & 0.26 & 2.28 & 0.95 & 32.69 & -0.60 & 0.97 \\
\hline Tampa & 1.34 & 0.37 & 2.97 & 1.26 & 17.23 & -0.45 & 1.00 \\
\hline Washington & 1.38 & 0.19 & 2.17 & 1.15 & 33.85 & -0.72 & 0.92 \\
\hline
\end{tabular}

\section{References}

American Community Survey, 2012. American Community Survey 2012, 1-year estimates. U.S. Census Bureau, Washington, D.C. (Accessed: 2014-09-30 online at: http://factfinder.census.gov/faces/tableservices/jsf/pages/productview.xhtml?pid= ACS_12_1YR_B08301\&prodType=table).

Ballou, R.H., Rahardja, H., Sakai, N., 2002. Selected country circuity factors for road travel distance estimation. Transp. Res. A Policy Pract. 36 (9), 843-848. http://dx.doi.org/10. 1016/S0965-8564(01)00044-1.

Barrington-Leigh, C., Millard-Ball, A., 2015. A century of sprawl in the United States. Proc. Natl. Acad. Sci. 112 (27), 8244-8249 (http://wellbeing.ihsp.mcgill.ca/publications/ Barrington-Leigh-Millard-Ball-PNAS2015-with-SI-1504033112.pdf).

Barthélemy, M., 2011. Spatial networks. Phys. Rep. 499 (13), 1-101. http://dx.doi.org/10. 1016/j.physrep.2010.11.002. 
Bar-Yosef, A., Martens, K., Benenson, I., 2013. A model of the vicious cycle of a bus line. Transp. Res. B Methodol. 54, 37-50. http://dx.doi.org/10.1016/j.trb.2013.03.010.

Black, A., 1995. Urban mass transportation planning. McGraw Hill, New York, NY.

Black, W.R., 2003. Transportation: a geographical analysis. Guilford Press, New York, NY.

Cao, X.J., Mokhtarian, P.L., Handy, S.L., 2009. The relationship between the built environment and non-work travel: a case study of Northern California. Transp. Res. A Policy Pract. 43 (5), 548-559. http://dx.doi.org/10.1016/j.tra.2009.02.001.

Cervero, R., 2004. Transit-oriented development in the United States: experiences, challenges, and prospects. vol. 102. Transportation Research Board, Washington, D.C. (http://onlinepubs.trb.org/onlinepubs/tcrp/tcrp_rpt_102.pdf).

Crucitti, P., Latora, V., Porta, S., 2006. Centrality in networks of urban streets. Chaos 16 (1), 015113. http://dx.doi.org/10.1063/1.2150162.

Date and Time, 2014. Online database. Date and Time, London, U.K. (Accessed: 2014-09-30 online at: http://dateandtime.info/).

Derrible, S., 2012. Network centrality of metro systems. PLoS One 7 (7), e40575. http://dx. doi.org/10.1371/journal.pone.0040575.

Derrible, S., Kennedy, C., 2009. Network analysis of world subway systems using updated graph theory. Transp. Res. Rec. 2112, 17-25 (http://trrjournalonline.trb.org/doi/pdf/ 10.3141/2112-03)

Derrible, S., Kennedy, C., 2010. The complexity and robustness of metro networks. Phys. A 389 (17), 3678-3691. http://dx.doi.org/10.1016/j.physa.2010.04.008.

Dijkstra, E.W., 1959. A note on two problems in connexion with graphs. Numer. Math. 1 269-271. http://dx.doi.org/10.1016/S1361-9209(98)00010-8.

Giacomin, D.J., Levinson, D.M., 2015. Road network circuity in metropolitan areas. Environ. Plan. B Plan. Des. 42. http://dx.doi.org/10.1068/b130131p (online first).

GTFS (General Transit Feed Specification), 2014. Exchange site Accessed: 2014-09-30 online at: http://www.gtfs-data-exchange.com/.

Krizek, K.J., 2003. Residential relocation and changes in urban travel: does neighborhoodscale urban form matter? J. Am. Plan. Assoc. 69 (3), 265-281. http://dx.doi.org/10 1080/01944360308978019.

Lam, T., Schuler, H., 1982. Connectivity index for systemwide transit route and schedule performance. Transp. Res. Rec. 854, 17-23 (http://trid.trb.org/view.aspx?id= 186850).

Lee, Y.J., 1998. Analysis and optimization of transit network design with integrated routing and scheduling (Ph.D. Dissertation), University of Pennsylvania, Philadelphia, PA (http://repository.upenn.edu/dissertations/AAI9840212/).

Lee, Y.J., 2008. Comparative measures for transit network performance analysis. J. Transp. Res. Forum 47 (3), 149-170 (http://www.trforum.org/journal/downloads/2008v47n3_09_ TransitNetworkPerformance.pdf).

Lee, Y.J., Choi, J.Y., Yu, J.W., Choi, K., 2015. Geographical applications of performance measures for transit network directness. J. Publ. Transp. 18 (2), 89-100. http://dx.doi.org/ 10.5038/2375-0901.18.2.7.

Levinson, D.M., 1998. Accessibility and the journey to work. J. Transp. Geogr. 6 (1), 11-21 http://dx.doi.org/10.1016/S0966-6923(97)00036-7.

Levinson, D.M., 2012. Network structure and city size. PLoS One 7 (1), e29721 (http:// journals.plos.org/plosone/article?id=10.1371/journal.pone.0029721).

Levinson, D.M., 2013. Access across America. University of Minnesota, Center for Transportation Studies, Minneapolis, MN (http://ao.umn.edu/research/america/auto/ 2013/).

Levinson, D.M., El-Geneidy, A., 2009. The minimum circuity frontier and the journey to work Reg. Sci. Urban Econ. 39 (6), 732-738. http://dx.doi.org/10.1016/j.regsciurbeco.2009.07. 003.

Levinson, D.M., Kumar, A., 1994. Multimodal trip distribution: structure and application. Transp. Res. Rec. 1466, 124-131.
Metropolitan Council and the Lawrence Group, 2015. Transit routes. Metropolitan Council, St. Paul, MN (Accessed: 2015-04-30 online at: http://datafinder.org/metadata/ TransitRoutes.html).

Mishra, S., Welch, T.F., Jha, M.K., 2012. Performance indicators for public transit connectivity in multi-modal transportation networks. Transp. Res. A Policy Pract. 46 (7), 1066-1085. http://dx.doi.org/10.1016/j.tra.2012.04.006.

Mohring, H., 1972. Optimization and scale economies in urban bus transportation. Am. Econ. Rev. 62 (4), 591-604 (http://www.jstor.org/stable/1806101).

Mokhtarian, P.L., Cao, X., 2008. Examining the impacts of residential self-selection on travel behavior: a focus on methodologies. Transp. Res. B Methodol. 42 (3), 204-228. http:// dx.doi.org/10.1016/j.trb.2007.07.006.

MTSA (Metropolitan Travel Survey Archive), 2007. Travel surveys. MTSA, Minneapolis, MN (Accessed: 2015-04-30 online at: http://www.surveyarchive.org/).

Murray, A.T., Davis, R., Stimson, R.J., Ferreira, L., 1998. Public transportation access. Transp. Res. Part D: Transp. Environ. 3, 319-328.

Newell, G.F., 1980. Traffic flow on transportation networks. Massachusetts Institute of Technology Press, Cambridge, MA (http://trid.trb.org/view.aspx?id=163763).

O'Sullivan, S., Morrall, J., 1996. Walking distances to and from light-rail transit stations. Transp. Res. Rec. 1538, 19-26 (http://trrjournalonline.trb.org/doi/pdf/10.3141/ 1538-03).

OSM (Open Street Map), 2014. Metro extracts Accessed: 2014-09-30 online at: https:// mapzen.com/metro-extracts/.

OTP (OpenTripPlanner), 2014. Data base Accessed: 2014-09-30 online at: http://www. opentripplanner.org/.

Owen, A., Levinson, D.M., 2014. Access across America, Technical Report CTS 14-11. University of Minnesota, Center for Transportation Studies, Minneapolis, MN (http:// www.cts.umn.edu/Publications/ResearchReports/reportdetail.html?id=2380).

Owen, A., Levinson, D.M., 2015. Modeling the commute mode share of transit using continuous accessibility to jobs. Transp. Res. A Policy Pract. 74, 110-122. http://dx.doi. org/10.1016/j.tra.2015.02.002.

Porta, S., Latora, V., Wang, F., Strano, E., Cardillo, A., Scellato, S., Iacoviello, V., Messora, R., 2009. Street centrality and densities of retail and services in Bologna, Italy. Environ. Plan. B Plan. Des. 36 (3), 450-465. http://dx.doi.org/10.1068/b34098.

Pratt, R.H., Turnbull, K.F., Evans, I.V., John, E., McCollom, B.E., Spielberg, F., Vaca, E., Kuzmyak, J.R., 1981. Traveler Response to Transportation System Changes: Interim Handbook (No. TCRP Project B-12). Federal Highway Administration, Washington, D.C. (http://ntl.bts.gov/lib/19000/19400/19442/PB2002106941.pdf).

Roth, C., Kang, S.M., Batty, M., Barthélemy, M., 2012. A long-time limit for world subway networks. J. R. Soc. Interface 9 (75). http://dx.doi.org/10.1098/rsif.2012.0259.

Taylor, B.D., 1991. Unjust equity: an examination of California's Development Act. Transportation Research Record 1297pp. 85-92 (http://www.uctc.net/papers/064.pdf).

TBI (Travel Behavior Inventory), 2013. Transport publications. Metropolitan Council, St. Paul, MN (Accessed: 2014-09-30 online at: http://www.metrocouncil.org/ Transportation/Publications-Resources-NEW.aspx).

Vragović, I., Louis, E., Díaz-Guilera, A., 2005. Efficiency of informational transfer in regular and complex networks. Phys. Rev. E 71 (3), 036122 (http://arxiv.org/pdf/cond-mat/ 0410174.pdf).

Walker, J., 2012. Human transit: how clearer thinking about public transit can enrich our communities and our lives. Island Press, Washington, D.C. (http://trid.trb.org/view. aspx?id=1147583). 